\title{
The influence of barrier coating parameters on the strength of metal matrix composites
}

\author{
P. V. Soloviev ${ }^{\dagger, 1}$, R. F. Gallyamova ${ }^{1,2}$, A. I. Gomzin ${ }^{1}$ \\ †paulnightingale@mail.ru \\ ${ }^{1}$ Ufa State Aviation Technical University, 12 K. Marx St., Ufa, 450008, Russia \\ ${ }^{2}$ Ufa Chemistry Institute UFIC RAS, 69 Oktyabra Av., Ufa, 450054 Russia
}

\begin{abstract}
In connection with the prospect of using metal matrix composites for various types of structural applications (in particular, thermally loaded elements of aviation and rocket-space technologies), recently more and more research has been focused on exploring the possibility of bonding controlling at a fiber-matrix interface, which, as a rule, is a weak point for composite materials of this type. In the case of carbon-aluminum composites, in order to fully reveal their strength properties, it is necessary to solve the problem with the formation of brittle aluminum carbide at the interface, drastically reducing the mechanical characteristics of composite materials. There are several ways to solve this problem, but the most promising is the application of barrier coatings, in particular oxide coatings, on the surface of the fibers. In this work, we have investigated the effect of single-layer, two-layer and three-layer coatings of titanium dioxide $\mathrm{TiO}_{2}$ deposited on carbon fibers by the solgel method, and heat treatment at $150^{\circ} \mathrm{C}, 350^{\circ} \mathrm{C}$ and $550^{\circ} \mathrm{C}$ for 1 hour on the strength of carbon-aluminum composites at three-point bending. It has been found that when using the sol-gel technology, titanium dioxide covers the fibers surface completely. In the microstructure of composites reinforced with uncoated and coated fibers, there are no pores or areas without impregnation. On average, the bending strength for carbon-aluminum specimens reinforced with uncoated fibers increases significantly after annealing, and the titanium dioxide coating in turn also contributes to an increase in the strength properties of the carbon-aluminum composite.
\end{abstract}

Keywords: composite, carbon fiber, strength, sol-gel method.

УДК: $621.763 ; 539.422 .5$

\section{Влияние параметров барьерного покрытия на прочность композитов с металлической матрицей}

\author{
Соловьев П. В. ${ }^{\dagger,}$, Галлямова Р. Ф., ${ }^{1,2}$, Гомзин А.И. ${ }^{1}$ \\ ${ }^{1}$ Уфимский государственный авиационный технический университет, ул. К. Маркса, 12, Уфа, 450008, Россия \\ 2Уфимский институт химии УФИЦ РАН, пр. Октября, 69, Уфа, 450054, Россия
}

Ввиду перспективности использования композитных материалов на металлической матрице для различного рода конструкционных применений (в частности, термонагруженных элементов авиационной и ракетно-космической техники), в последнее время все больше исследований направлено на изучение возможности управления связью на границе «волокно-матрица», которая, как правило, является слабым местом для композиционных материалов такого типа. В случае углеалюминиевых композитов, для полного раскрытия их прочностных свойств необходимо решить проблему с образованием хрупкого карбида алюминия на межфазной границе, резко снижающего механические характеристики композиционных материалов. Существует несколько способов решения данной проблемы, однако наиболее перспективным является нанесение на поверхность волокон барьерных покрытий, в частности оксидных. В настоящей работе было исследовано влияние однослойного, двуслойного и трёхслойного покрытий из диоксида титана $\mathrm{TiO}_{2}$, нанесенных на углеродные волокна при помощи золь-гель метода, и термической обработки при $150^{\circ} \mathrm{C}, 350^{\circ} \mathrm{C}$ и $550^{\circ} \mathrm{C}$ в течение 1 часа на прочность углеалюминиевых композитов при трехточечном изгибе. Было установлено, что при использовании золь-гель технологии диоксид титана покрывает поверхность волокон полностью. В микроструктуре композитов, армированных волокнами с покрытиями и без, отсутствуют поры и области без пропитки. В среднем предел прочности при изгибе для образцов углеалюминия, армированных углеродными волокнами без $\mathrm{TiO}_{2}$ покрытия, после проведения отжигов значительно возрастает, а покрытие диоксида титана в свою очередь также способствует повышению прочностных свойств углеалюминиевого композита.

Ключевые слова: композит, углеродное волокно, прочность, золь-гель метод. 


\section{1. Введение}

Композитные материалы (КМ) находят все большее применение в наукоемких отраслях производства, позволяя создавать конструкции с более высокими удельными характеристиками, в первую очередь прочностью и жесткостью. Однако проектировать изделия из композитов значительно сложнее вследствие таких особенностей КМ, как анизотропия упругих и прочностных свойств, низкие прочность и жесткость при поперечном растяжении/сжатии и сдвиге, а также из-за существенного влияния разнообразных технологических факторов на конечные свойства композита. Особенно сильно это влияние сказывается на композитах с металлической матрицей вследствие высокой реакционной способности матричного материала по отношению к армирующему (особенно в расплавленном состоянии).

Решить проблему можно либо изготовлением металломатричных композитов по твердофазной технологии, когда матричный материал не расплавляется, либо использованием различных барьерных покрытий, защищающих армирующие волокна от взаимодействия с расплавом матрицы.

В случае создания металломатричных композитов, армированных углеродным волокном (УВ), использование твердофазной технологии не представляется возможным ввиду малого диаметра УВ (5-10 мкм). При таком диаметре заполнение всего межволоконного пространства возможно только жидкой матрицей. В связи с этим основным методом ограничения химического взаимодействия между волокном и расплавом металла является нанесение защитных покрытий.

Разработка таких покрытий позволит раскрыть весь потенциал механических характеристик армирующих волокон в сочетании с высокими жесткостными свойствами металлической матрицы и ее теплостойкостью. Решение этой задачи позволит расширить температурный диапазон использования КМ в «горячих» элементах конструкций современных авиастроения, автомобилестроения и других отраслей машиностроения, ограниченный на данный момент верхней температурой длительной работоспособности полимерных связующих, обычно не превышающей $200-250^{\circ} \mathrm{C}$.

Одним из самых перспективных способов нанесения защитных покрытий на волокна является золь-гель метод $[1,2]$. Этот метод не требует какого-то специального дорогостоящего оборудования и создания специальных условий, как, например, метод химического осаждения из газовой фазы. С помощью золь-гель технологии возможно получение тонких керамических пленок не только на разного рода волокнах, но и на любых поверхностях различных материалов.

В связи с вышеперечисленным, данный метод представляет большой интерес для современных исследователей КМ, в частности, композитов с армированием волокнами (как дискретными, так и непрерывными). Золь-гель технология может быть применима даже в случае использования полимерной матрицы для улучшения взаимодействия компонентов [3].
Однако больше всего золь-гель технология востребована при изготовлении металломатричных композитов: либо для усиления связи на границе «волокно-матрица» [4], либо для снижения химического взаимодействия между компонентами и предотвращения образования нежелательных фаз [5].

К композитам последнего вида относятся композиты на основе непрерывных УВ и алюминия и его сплавов. Углеалюминиевые композиты являются весьма перспективными ввиду высоких удельных характеристик, однако добиться расчетной прочности не позволяет образование карбида алюминия $\mathrm{Al}_{4} \mathrm{C}_{3}$ на границе «волокно-матрица» $[6,7]$. Был предпринят ряд попыток решить эту проблему, применяя легирование матрицы [8-10], различные схемы получения композита $[11,12]$ и УВ с различной структурой $[7,13]$. Защитные покрытия, наносимые с помощью сложного дорогостоящего оборудования, также применяются при создании углеалюминиевых композитов [8,14]. Известны исследования, в которых на УВ защитное покрытие наносилось и упомянутым ранее золь-гель методом [15]. Однако работ в области оценки влияния оксидного покрытия, нанесенного золь-гель методом, на прочностные характеристики композита с чистой алюминиевой матрицей, армированной высокопрочными УВ, на данный момент в открытой печати не имеется. Вопрос, касающийся изучения влияния термической обработки на прочность углеалюминиевого композита, армированного волокнами с оксидным покрытием, в современной научной литературе также не нашел должного отражения.

Все вышесказанное делает исследования, проводимые в данной работе и посвященные анализу влияния многослойных барьерных покрытий, нанесенных на УВ золь-гель методом, и серии отжигов на прочностные свойства углеалюминиевых композитов, актуальными, имеющими научную новизну и практическую ценность.

\section{2. Материал и методы исследования}

В качестве материала армирования использовалась однонаправленная углеродная ткань марки UMT49-12K-EP (Россия), а в качестве материала матрицы алюминий технической чистоты A7 с массовой долей алюминия не менее 99.7\%. Предварительно углеродная ткань подвергалась термообработке при температуре $400^{\circ} \mathrm{C}$ в течение 20 минут для удаления с поверхности полимерного аппрета [16]. Процесс получения золь-гель раствора подробно описан в [17]. В качестве источника $\mathrm{TiO}_{2}$ использовался бутоксид титана $\mathrm{Ti}\left(\mathrm{OC}_{4} \mathrm{H}_{9}\right)_{4}$. В смесь (бутанол, уксусная кислота, ацетилацетон) добавляется бутоксид титана. После перемешивания в течение 1 часа медленно по каплям добавляется смесь из дистиллированной воды и бутанола. Весь полученный раствор интенсивно перемешивается в течение 1 часа. Приготовленный зольгель раствор выдерживался 3 дня при комнатной температуре, для того чтобы активизировались процессы гидролиза. Нанесение покрытия производилось по схеме: выдержка углеродной ткани в золь-гель растворе 
в течение 5 минут, с дальнейшей сушкой при комнатной температуре в течение 30 мин, затем медленный нагрев до температуры $500^{\circ} \mathrm{C}$ (скорость нагрева $2.5^{\circ} \mathrm{C} /$ мин), выдержка при данной температуре 30 мин. На поверхность ткани наносили одно-, двухи трехслойное покрытия.

Композиты, армированные непрерывным УВ без покрытия и с покрытием, были получены методом жидкофазной пропитки под давлением (пакетной формовкой). Технология получения углеалюминиевых пластин описана в [18], в данном исследовании давление прессования составило 45 МПа. В связи с отсутствием ГОСТа для механических испытаний на трехточечный изгиб КМ с металлической матрицей, испытания углеалюминиевых композитов были проведены в соответствии с ГОСТ Р 56810-2015. Полученные образцы подвергались отжигу при температурах $150^{\circ} \mathrm{C}$, $350^{\circ} \mathrm{C}$ и $550^{\circ} \mathrm{C}$ в течение одного часа. Поверхность и морфология образцов изучалась на растровом электронном микроскопе (JEOL JSM-6490LV). Качественная и количественная оценка содержания химических элементов проводилась с использованием системы для энергодисперсионного микроанализа INCA Energy, которой оснащен РЭМ.

\section{3. Результаты и их обсуждение}

\section{1. Структура $\mathrm{TiO}_{2}$ покрытия}

В исходном состоянии УВ характеризуются фибриллярным строением, на которых содержится множество продольных полос, расположенных параллельно друг другу (Рис. $1 \mathrm{Sa}$, дополнительный материал). После удаления слоя полимерного аппрета поверхность волокон стала более рельефной - продольные полосы стали глубже и отчетливее просматривались на снимках (Рис. 1Sb, дополнительный материал).

На Рис. 1 представлены изображения поверхности УВ после нанесения $\mathrm{TiO}_{2}$ покрытия золь-гель методом. Процесс нанесения золь-гель раствора на поверхность УВ сопровождается испарением компонентов золя (растворителя и воды) и осаждением оксида титана. На стадии термической обработки развиваются трещины и отслоения из-за различного коэффициента

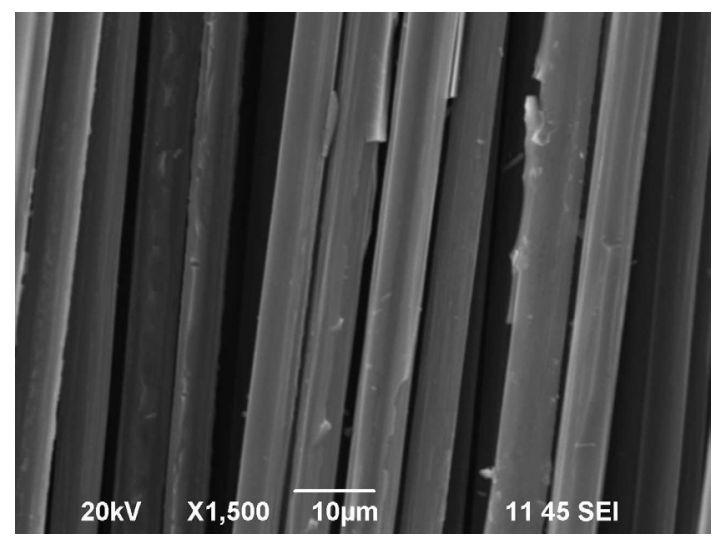

a термического расширения волокна и покрытия. Как видно из Рис. 1b, с увеличением количества слоев покрытия увеличивается количество осажденных частиц исходного золя на поверхности волокон, негативным следствием чего является предпосылка к растрескиванию покрытия из-за внутренних напряжений. На всех образцах сформировалось несколько неравномерное покрытие, также присутствует некоторое количество участков без покрытия. По результатам микроструктурных исследований можно сделать предварительный вывод о том, что увеличение количества слоев покрытия более трех нерационально.

\section{2. Механические испытания углеалюминиевого композита}

Методом жидкофазной пропитки под давлением были получены 4 серии образцов углеалюминиевых композитов в виде пластин с различным количеством слоев оксида на УВ. Во всех образцах наблюдалась полная пропитка, и все образцы имели характерную для однонаправленного композита микроструктуру в плоскости, нормальной к направлению укладки волокон (Рис. 2S, дополнительный материал). Такая структура представляет собой множество волокон в поперечном сечении (в данном случае округлой формы), распределенных по матрице без строгой периодичности. Данная структура типична для подавляющего большинства однонаправленных композитов.

Каждая из исходных пластин была разделена на образцы вдоль направления укладки волокон с поперечным сечением прямоугольной формы для проведения механических испытаний на трехточечный изгиб. Затем образцы были отожжены и испытаны на изгибную прочность. Режим обработки и средние значения прочности образцов указана в Табл. $1 \mathrm{~S}$ (дополнительный материал). Более наглядно данные по прочности образцов представлены графически в виде кривых (Рис. 2).

Как видно из Рис. 2, наибольшее влияние термообработка оказала на образцы, армированные УВ без покрытия. На этом образце после отжига при $150^{\circ} \mathrm{C}$ предел прочности возрос почти в 2 раза - со $105 \mathrm{MПа}$ до 198 МПа. До температуры отжига $350^{\circ} \mathrm{C}$ включительно прочность данного образца возрастает, а затем
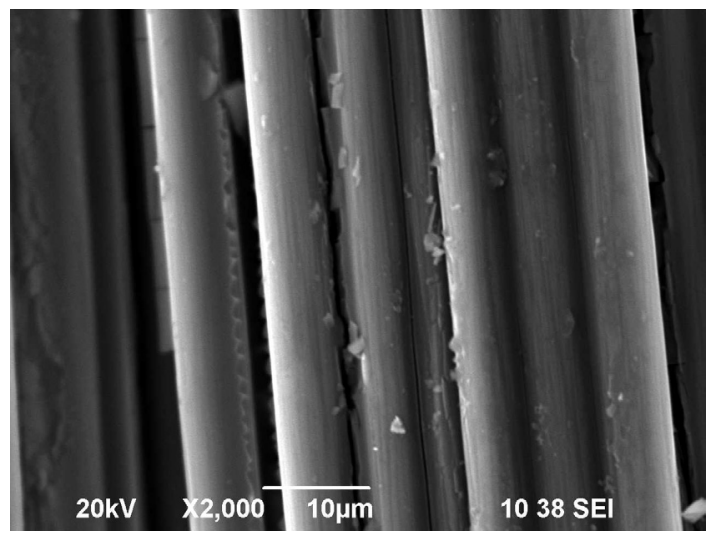

b

Рис. 1. Поверхность углеродных волокон после нанесения $\mathrm{TiO}_{2}$ покрытия методом золь-гель: 1 слой (a), 3 слоя (b).

Fig. 1. Carbon fiber surface after $\mathrm{TiO}_{2}$ deposition by the sol-gel method: 1 layer (a); 3 layers (b). 


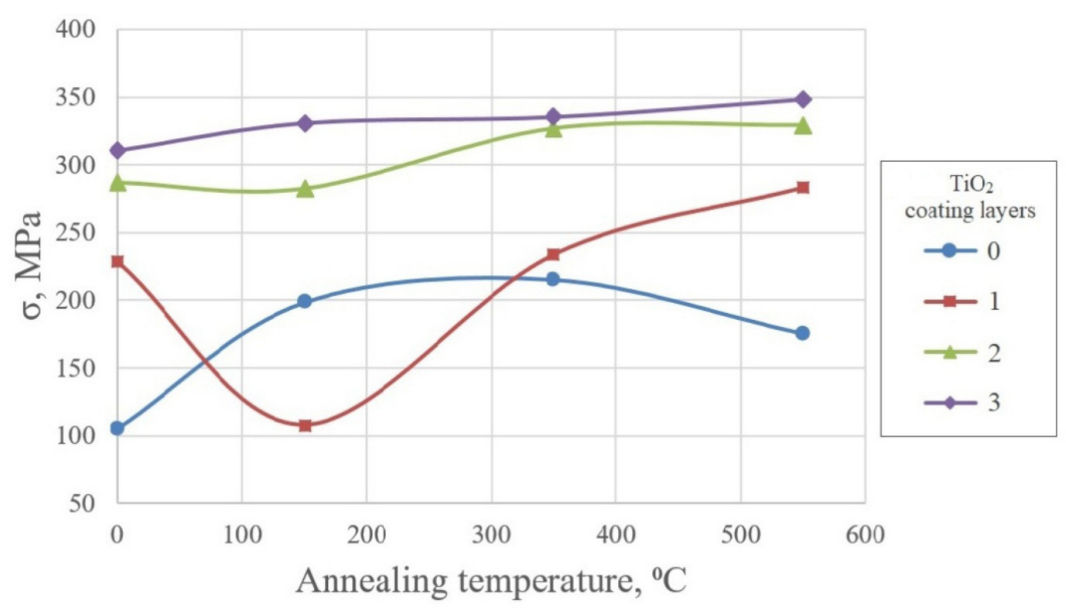

Pис. 2. (Color online) Зависимость прочности при изгибе композитных образцов с покрытием и без на волокнах от температуры отжига. Fig. 2. (Color online) Dependence of the bending strength of composite specimens with and without coating on fibers on annealing temperature.

снижается. Стоит отметить значительное снижение прочности на кривой для образцов с одинарным покрытием для температуры $150^{\circ} \mathrm{C}$ : данная ситуация, скорее всего, является результатом появления дефектов в образце до проведения механических испытаний, во время извлечения композитной пластины из стальной оболочки (часть процесса получения композита методом пакетной формовки), и не является закономерностью.

В случае образцов с покрытиями прочность монотонно возрастает до температуры $550^{\circ} \mathrm{C}$, при этом с увеличением толщины покрытия на образцах прирост прочности становится меньше. Так увеличение средней прочности для композита с одинарным покрытием составило $25 \%$, а для образца с тройным покрытием $12 \%$. Тем не менее, реальные показатели прочности намного меньше теоретических значений: по правилу смесей [19] теоретическая прочность композита с объемной долей волокна в 30\% должна составлять 1500 МПа, a на практике максимальная прочность составляет порядка 350 МПа.

Вероятно, такие низкие показатели объясняются образованием хрупкого карбида алюминия $\mathrm{Al}_{4} \mathrm{C}_{3}$ на границе УВ и алюминиевой матрицы, образующегося по простой реакции $4 \mathrm{Al}+3 \mathrm{C} \rightarrow \mathrm{Al}_{4} \mathrm{C}_{3}$.

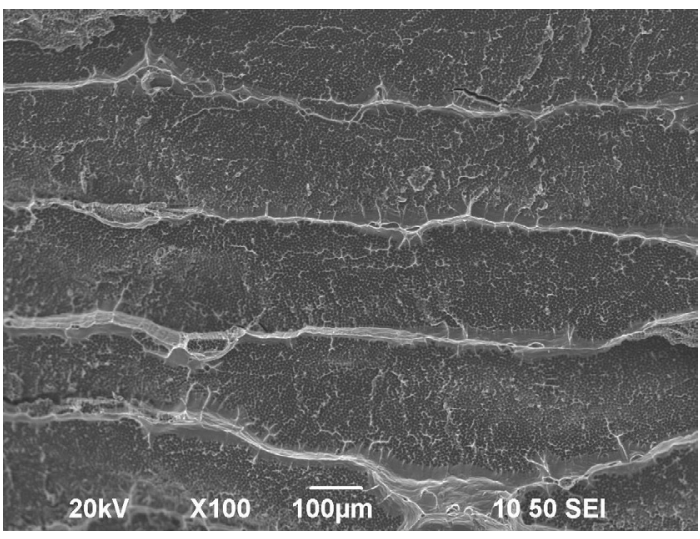

a
Во многих работах было неоднократно показано существование кристаллов карбида алюминия в форме пластин или иголок, которые росли с поверхности УВ в сторону алюминиевой матрицы. При этом кристаллы $\mathrm{Al}_{4} \mathrm{C}_{3}$ имеют размеры порядка десятков и сотен нанометров в ширину и в длину, соответственно $[8,9]$. Кроме того, карбид алюминия является гигроскопичным и при воздействии влаги, содержащейся даже в атмосферном воздухе, разлагается [9]. Эти два фактора делают невозможным наблюдение $\mathrm{Al}_{4} \mathrm{C}_{3}$ при помощи оптического и растрового электронного микроскопов. Однако в работах $[8,9]$ указывается на негативное влияние карбида на прочностные свойства композита, поэтому прочность зависит от количества образовавшегося карбида алюминия.

С ростом прочности углеалюминия излом должен становиться более рельефным, отдельные пучки и волокна должны возвышаться над основной поверхностью разрушения. Однако в серии образцов углеалюминия, армированного УВ без покрытия, характер излома всех композитов идентичен (Рис. 3), что, вероятнее всего, связано с образованием кристаллов карбида алюминия, являющихся причиной очень высокой адгезии и легкого распространения трещины, во всех образцах.

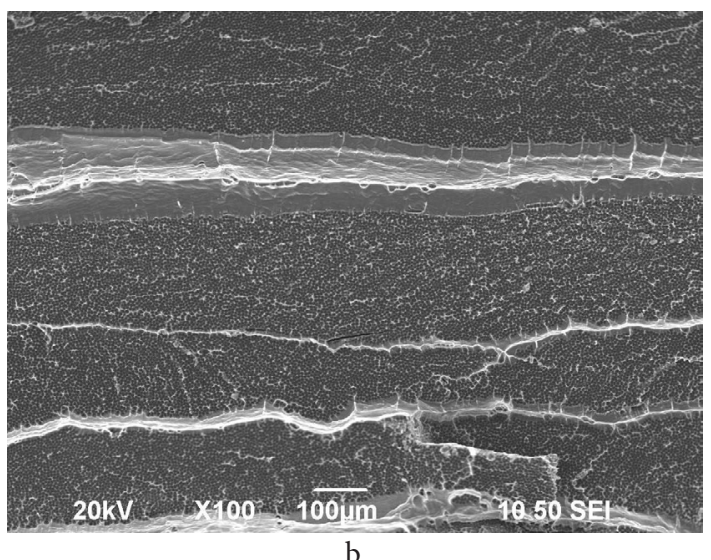

Рис. 3. Поверхности разрушения образцов углеалюминия с волокнами без покрытия: образец без отжига (a); образец после отжига при $550^{\circ} \mathrm{C}(\mathrm{b})$.

Fig. 3. Specimen failure surfaces $\mathrm{Cf} / \mathrm{Al}$ composite with uncoated fibers: not annealed specimen (a); specimen annealed at $550^{\circ} \mathrm{C}(\mathrm{b})$. 
В то же время, образцы даже с тройным покрытием на волокнах, показывающие более высокие значения прочности, при малом увеличении имеют идентичный рельеф до и после отжигов (Рис. 3S, дополнительный материал).

При большем увеличении заметны некоторые различия в характере разрушения композитов. В образцах с меньшей прочностью поверхность разрушения плоская и практически ровная, волокно и алюминий плотно прилегают друг к другу (Рис. 4a). У образца с тройным покрытием после отжига при $550^{\circ} \mathrm{C}$, имеющего большую прочность, алюминиевая матрица в большинстве случаев отделена от волокна, что свидетельствует о меньшей адгезии волокна и матрицы, и меньшего количества выделившихся карбидов (Рис. 4b). Судя по ряду работ, данный признак и является показателем менее сильной связи матрицы и волокна, а значит, большей диссипации энергии в вершине трещины, что приводит к большей прочности КМ $[5,6,20]$. Как было показано, в настоящем исследовании эта закономерность в отношении прочности и характера разрушения также подтверждается.

После проведения отжигов изгибная прочность композитов возрастает. Можно предположить, что данное явление связано с релаксацией остаточных напряжений в материале, которые появляются после охлаждения композита в процессе изготовления из-за разницы КТР матрицы и волокон $[21,22]$. При этом, возможно, значительная часть напряжений связана именно с образованием и ростом карбидов алюминия [23], поэтому и влияние термообработки на прочность образцов углеалюминия уменьшается с увеличением толщины покрытия, т. к. с увеличением толщины покрытия снижается количество образовавшихся карбидов алюминия. Предел прочности образца, армированного волокном без покрытия, снижается после отжига при $550^{\circ} \mathrm{C}$, что можно объяснить тем, что увеличение количества карбида алюминия перекрывает положительный эффект релаксации остаточных напряжений материала.

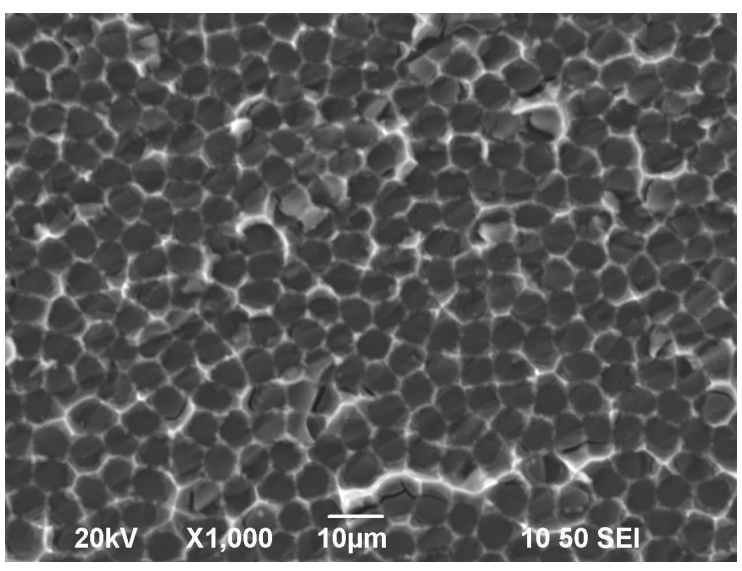

a

\section{4. Выводы}

В результате проведенных исследований были сделаны следующие заключения.

1. Увеличение количества слоев $\mathrm{TiO}_{2}$ покрытия приводит к большему растрескиванию на поверхности волокон. В связи с этим на участках, где покрытие отсутствует, существует большая вероятность образования карбида алюминия.

2. Средний предел прочности при изгибе композитных образцов без покрытия при отжигах до температуры $350^{\circ} \mathrm{C}$ включительно возрастает примерно в 2 раза. Средний предел прочности при изгибе образцов, армированных УВ с покрытием диоксида титана, до температуры $550^{\circ} \mathrm{C}$ включительно возрастает на $25 \%, 15 \%, 12 \%$ для одинарного, двойного, тройного покрытий, соответственно.

3. Результаты фрактографических исследований поверхностей разрушения коррелируют со значениями прочности образцов. Плоские изломы свидетельствуют об образовании кристаллов карбида алюминия на границе волокна с матрицей, снижающих прочность материала. Увеличение количества слоев $\mathrm{TiO}_{2}$ покрытия и увеличение температуры отжигов ведет к росту прочности, что, скорее всего, связано с уменьшением количества выделившихся кристаллов карбида алюминия и релаксацией остаточных напряжений

Таким образом, в данной работе показано, что нанесение $\mathrm{TiO}_{2}$ покрытия золь-гель методом является эффективным и перспективным направлением для увеличения прочности углеалюминия, а дополнительные исследования по поиску оптимального режима нанесения оксидного покрытия могут обеспечить получение еще более высоких прочностных характеристик углеалюминиевого композита.

Дополнительный материал/Supplementary Material. Электронная версия статьи содержит дополнительный материал, доступный безвозмездно на сайте журнала (lettersonmaterials.com)./The online version of this paper contains supplementary material available free of charge at the journal's Web site (lettersonmaterials.com).

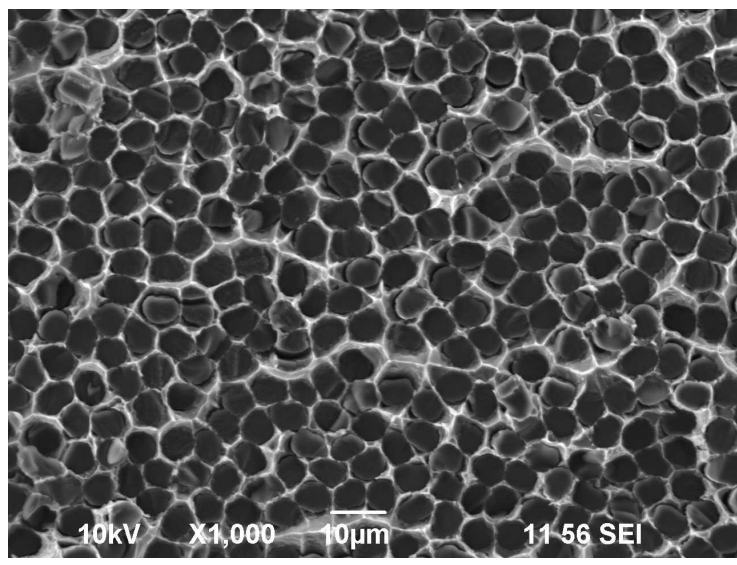

$\mathrm{b}$

Рис. 4. Поверхности разрушения образцов углеалюминия после отжига при $550^{\circ} \mathrm{C}$ без покрытия (a), с тройным покрытием (b).

Fig. 4. The fracture surfaces of $\mathrm{Cf} / \mathrm{Al}$ composite specimens annealed at $550^{\circ} \mathrm{C}$ without coating (a), with a three-layer coating (b). 
Благодарности/Acknowledgements. Исследование выполнено при финансовой поддержке РФФИ в рамках научного проекта № 18-33-00351./The reported study was funded by RFBR according to the research project № 18-33-00351.

\section{Литература/References}

1. T. Wen, J. Gao, J. Shen, Z. Zhou. J. Mater. Sci. 36, 5923 (2001). Crossref

2. R.F.Gallyamova, S. N.Galyshev,F.F.Musin,A.G.Badamshin, V.A. Dokichev. SSP: Materials Engineering and Technologies for Production and Processing IV. 284. 1242 (2018). C. Crossref

3. A. Szczurek, M. Barcikowski, K. Leluk, B. Babiarczuk, J. Kaleta, J. Krzak. Materials. 10, 990 (2017). Crossref

4. W. G. Wang, B. L. Xiao, Z. Y. Ma. Compos. Sci. Technol. 72, 152 (2012). Crossref

5. Z.L. Pei, K. Li, J. Gong, N.L. Shi, E. Elangovan, C. Sun. J. Mater. Sci. 44, 4124 (2009). Crossref

6. A. Feldhoff, E. Pippel, J. Woltersdorf. Adv.Eng. Mater. 2 (8), 471 (2000). Crossref

7. Z. Yunhe, W. Gaohui. Rare Metals. 29 (1), 102 (2010). Crossref

8. M.H. Vidal-Sétif, M. Lancin, C. Marhic, R. Valle, J.-L. Raviart, J.-C. Daux, M. Rabinovitch. Mater. Sci. Eng. A. 272, 321 (1999). Crossref

9. X. Wang, D. Jiang, G. Wu, B. Li, P. Li. Mater. Sci. Eng. A. 497, 31 (2008). Crossref

10. T. Matsunaga, K. Matsuda, T. Hatayama, K. Shinozaki, S. Amanuma, M. Yoshida. J. jpn. I. met. 56 (2), 105 (2006). Crossref

11. T. Matsunaga, K. Ogata, T. Hatayama, K. Shinozaki, M. Yoshida. J. jpn. I. met. 56 (4), 226 (2006). Crossref
12. M. Gude, A. Boczkowska. Textile reinforced carbon fibre-aluminium matrix composites for lightweight applications. Cracow, Foundry Research Institute (2014) $235 \mathrm{p}$.

13. J. Mikuni, K. Nonokawa, T. Matsunaga, K. Shinozaki, M. Yoshida. J. jpn. I. met. 58 (1), 27 (2008). Crossref

14. J. K. Yu, H.L. Li, B. L. Shang. J. Mater. Sci. 29 (10), 2641 (1994). Crossref

15. J.P. Clement, H. J. Rack, K. T. Wu, H. G. Spencer. Mater. Manuf. Process. 5 (1), 17 (1990). Crossref

16. M.I. Valuyeva, I.V. Zelenina, M.A. Khaskov, A.I. Gulyayev. Trudy VIAM. 10 (58), 79 (2017). (in Russian) [М.И. Валуева, И. В. Зеленина, М. А. Хасков, А. И. Гуляев. Труды ВИАМ. 10 (58), 79 (2017).]

17. H. Hu, B. Pang, Y. Zhu, Y. Fu. Text. Res. J. 87 (18), 1 (2016). Crossref

18. S. Galyshev, A. Gomzin, F. Musin. Mater. Today. Proc. 11, 281 (2019). Crossref

19. Yu.S. Pervushin, P.V. Solovyev. Vestnik Samarskogo Gosudarstvennogo Tekhnicheskogo Universiteta. Seriya «Tekhnicheskiye nauki». 1 (33), 99 (2012). (in Russian) [Ю. С. Первушин, П. В. Соловьев. Вестник Самарского Государственного Технического Университета. Серия «Технические науки». 1 (33), 99 (2012).]

20. S. Li, L. Qi, T. Zhang, L. Ju, H. Li. Micron. 101, 170 (2017). Crossref

21. M. Vedula, R. N. Pangborn, R. A. Queeney. Composite. 19 (1), 55 (1988). Crossref

22. A. Öchsner, G.E. Murch. Heat Transfer in Multi-Phase Materials. Springer, Berlin Heidelberg (2011) 460 p. Crossref

23. H.-D. Steffens, B. Reznik, V. Kruzhanov, W. Dudzinski. J. Mater. Sci. 32, 5413 (1997). Crossref 